\title{
BENTURAN IM PERIALISME BUDAYA BARAT DAN BUDAYA TIMUR DALAM MEDIA SOSIAL
}

\author{
Okeu Yudipratomo \\ Universitas Indonesia \\ okeuyudipratomo@gmail.com
}

\begin{abstract}
Abstrak
Media sosial di era saat ini melebur menjadi sebuah kebutuhan primer untuk aktualisasi diri, dengan pengguna tanpa batas dan dapat diakses kapanpun dimanapun di seluruh dunia menjadikan konten dalam media sosial menjadi sebuah isu yang menarik terkait imperialisme. Pengakuan akan budaya dan norma masing-masing yang ada di dalam media sosial membuat sebuah tekanan yang dapat memicu benturan budaya. Hal tersebut dikarenakan adanya faktor kemudahan akses dalam berselancar di media sosial. Hal yang menarik dalam fenomena ini adalah sebuah konsumsi dari produk-produk budaya yang ditampilkan secara ringkas namun sarat akan makna yang disebarkan melalui media sosial. Fokus kajian ini adalah mengkaji benturan antara budaya barat dan budaya timur di dalam konten media sosial melalui paham imperialisme, orientalisme dan oksidentalisme secara konseptual. Kedua paham budaya tersebut mewakili budaya dan harfiahnya masing-masing dalam menunjukkan kualitas dalam kehidupan. Penyerapan informasi dari konten yang tersedia di media sosial diantara kedua budaya tersebut dapat menjadi subjektif dan mempengaruhi sikap. Dalam kajian konseptual ini menggambarkan pengguna media sosial yang terlibat dengan narasi sosial yang panjang atau konten media sosial yang kompleks menjadikan cultural crossfit atau persilangan budaya menjadi salah satu aspek dalam terjadinya benturan.
\end{abstract}

Kata Kunci: Media Sosial, Imperialisme Budaya, Orientalisme, Oksidentalisme, Konten Media Sosial

\begin{abstract}
In the current era, social media has merged into a primary need for selfactualization, with unlimited users and can be accessed anytime anywhere in the world, making content on social media an interesting issue related to imperialism. The recognition of each other's culture and norms in social media creates a pressure that can trigger a clash of cultures. The pressure comes due to the ease of access factor in surfing on social media. The exciting thing in this phenomenon is the consumption of cultural products presented briefly but full of meaning spread through social media. This study focuses on examining the clash between western and eastern cultures in social media content through
\end{abstract}


conceptual imperialism, orientalism and occidentalism. The two cultural understandings represent a culture and their literal each other in showing quality in life. The absorption of information from content available on social media between the two cultures can be subjective and affect attitudes. This conceptual study describes social media users who are involved with long social narratives or complex social media content, making cultural crossfit one of the aspects in the occurrence of a collision.

Keywords Cultural Imperialism, Occidentalism, Orientalism, Social M edia, Social Media Content

\section{Pendahuluan}

Kehidupan manusia abad ini tidak terlepas dari media dan segala bentuk informasi yang membaur didalamnya. Media menjadi sebuah komoditas primer informasi serta hiburan bagi semua kalangan masyarakat di seluruh penjuru dunia dengan one stops entertainment yang dimilikinya. Kecepatan akses informasi yang didukung banyak sekali teknologi canggih melalui gawai dan peranti pendukung lainnya yang membuat seluruh dunia terhubung tanpa ada batasan, terlebih hadirnya berbagai jenis media sosial. Setiap harinya, masyarakat dunia mengakses media sosial melalui gawai pintar untuk sekadar mengisi waktu senggang maupun mencari informasi yang sedang dibutuhkan.

Penetrasi informasi dan budaya dari seluruh penjuru dunia ke media sosial bagi masyarakat dunia tidak dapat terbendung karena efek dari luasnya cakupan media sosial. Hal yang menarik dalam fenomena ini adalah sebuah konsumsi dari produk-produk budaya yang ditampilkan secara ringkas namun sarat akan makna yang disebarkan melalui media sosial. Mark Poster (Littlejohn \& Foss, 2011) mengungkapkan periode baru dimana teknologi interaktif dan komunikasi jaringan khususnya dunia maya akan mengubah masyarakat dan kekuatan media menjadi fokus utama dalam penyebaran konten. Berdasarkan hasil riset yang dikemukakan oleh We Are Social dalam Global Digital Report 2018 (We Are Social \& Hootsuite, 2018), dunia saat ini memiliki tiga besar 
aplikasi sosial media yang frekuensi pemakaiannya sangat sering digunakan dalam penyebarluasan konten yaitu Facebook, Youtube, Instagram. Kontenkonten dalam media sosial tersebut memiliki kategori yang dapat diklasifikasikan sebagai berikut: (1) kategori informasi berupa iklan, berita, tips dan trik (2) kategori hiburan berupa olahraga, otomotif, humor, video musik, drama, web series, vlog, infotainment dan reality show (3) kategori pendidikan berupa dakwah agama, pengetahuan umum, film dokumenter dan penelitian ilmiah. Cara penyampaian konten dapat dibagi menjadi teks, foto dan video. Melalui kategori tersebut, masyarakat dunia mencari dan memilih konten secara bebas sesuai dengan keinginan dan kebutuhannya. Seiring waktu penggunaan internet dan media sosial, di tahun 2020, aplikasi TikTok yang merupakan aplikasi berfitur konten video kreatif kini menjadi platform media sosial yang secara signifikan digunakan (Hootsuite, 2020) dan menjadi bagian penting dalam pertukaran informasi melalui konten.

Masyarakat dunia yang heterogen membentuk sebuah peradaban budaya yang berbeda satu sama lain, budaya adalah suatu keseluruhan kompleks yang meliputi pengetahuan, kepercayaan, kesenian, moral, keilmuan, hukum, adat istiadat, dan kemampuan yang lain serta kebiasaan yang didapat oleh manusia sebagai anggota masyarakat (Setiadi, 2012). Dengan budaya yang dimiliki, pola budaya yang dibangun oleh masyarakat dunia menjadi perbedaan yang sangat kuat dan dapat menjadi alat propaganda yang efektif dan dapat menimbulkan efek perang maya. M eningkatnya perluasan cakupan media saat ini memberikan kesadaran kepada publik bahwa dunia maya bisa menjadi arena peperangan budaya baik antar individu maupun antar kelompok. Bentrok yang terjadi di media sosial akan berkembang ketika masing-masing budaya yang berbeda tidak dapat menerima perbedaan sikap dan beranggapan bahwa budaya luar merupakan hal yang tidak pantas untuk ditiru dan diadaptasi. 


\section{Masyarakat Kelompok Barat dan Kelompok Timur}

Kluster masyarakat dunia dipisahkan menjadi dua bagian, yaitu bagian barat dan bagian timur. Masyarakat barat dan timur secara faktual memang dipisahkan oleh benua yang berbeda, namun, pembagian masyarakat kelompok barat dan kelompok timur bukan didasari oleh letak geografis, namun penetapan kluster ini ditandai oleh faktor-faktor fisiologis, psikologis, budaya dan sejarah yang melatarbelakangi. Kesamaan yang terbentuk dari masing-masing individu hingga menjadi suatu kelompok budaya menjadikan asosiasi budaya semakin rekat dan erat, tidak dapat dipisahkan karena statusnya menjadi seragam. Masyarakat kelompok barat menekankan ilmu dan logika serta cenderung aktif dan beranalisis (Sulaeman, 2015). Pikiran masyarakat kelompok barat cenderung objektif dibandingkan dengan menggunakan rasa, pengetahuan menjadi dasar empiris yang kuat yang mengesampingkan cara pandang hidup tradisional dan agamis.

Cara berpikir masyarakat kelompok barat lebih terpikat kepada kemajuan material, sehingga tidak begitu cocok dengan cara berpikir untuk melihat makna hidup dan makna dunia. Filsafat tradisional dan agama bagi masyarakat kelompok barat hanya muncul sebagai sistemik ide-ide abstrak tanpa ada hubungannya dengan kenyataan dan praktek hidup. Ada tiga ciri dominan yang dimiliki oleh masyarakat kelompok barat (1) penghargaan terhadap martabat manusia seperti demokrasi dan kesejahteraan (2) kebebasan seperti mengungkapkan pendapat dan kebebasan dalam berpakaian (3) penciptaan dan pemanfaatan teknologi.

Wilayah residensial masyarakat kelompok barat secara geografis terletak di bagian barat dunia, yaitu benua Amerika dan Eropa, namun secara kultural lebih dari itu, kolonialisme atau wilayah jajahan juga mempengaruhi kecondongan masyarakat yang terjajah mengikuti sifat dan kebudayaan yang dibawa oleh penjajah atau pendatang. Secara letak geografis Afrika berada di tengah-tengah bagian dunia, secara sejarah, Afrika bagian tengah hingga selatan 
pernah dijajah oleh bangsa Eropa dan Amerika, sehingga terjadi pembentukan hegemoni budaya yang kental pascakolonialisme (Friedman, 2009). Begitu pula Australia, negara yang termasuk ke dalam commonwealth secara sejarah lebih mengikuti kebudayaan yang dilakukan oleh masyarakat kelompok barat.

Masyarakat kelompok timur bermukim di bagian timur dunia, yaitu benua Asia dan sebagian Afrika bagian utara dilihat dari sejarah yang melatarbelakanginya. Dalam budayanya, masyarakat kelompok timur memiliki perspektif yang berbeda dari masyarakat kelompok barat, menjunjung tinggi terhadap norma bersumber dari ajaran agama yang lahir di dunia timur. Kepribadian masyarakat kelompok timur terletak pada rasa, bukan kepada intelektualnya. Nilai budaya timur terbentuk melalui cara berpikir kontemplatif sebagai puncak dari perkembangan intuisi manusia. Kebudayaan masyarakat kelompok timur tidak hanya bersumber dari agama tetapi ide abstrak dan simbol menjadi hal yang konkret dalam praktek kehidupananya. Dalam kenyataannya, masyarakat kelompok timur tidak hanya menambah pengetahuan kognitif saja, tetapi juga mencari sebuah kebijaksanaan yang terdapat didalamnya. Memadukan pengetahuan, intuisi, pemikiran konkret, simbolik dan kebijaksanaan yang nampak pada keharmonisan antara norma perilaku.

Pandangan secara garis besar masyarakat kelompok barat dan kelompok timur menyisakan hal yang penting untuk dibahas lebih lanjut, klasifikasi kelompok masyarakat yang memiliki percampuran budaya barat dan timur atau terjadinya transmigrasi kelompok barat ke timur maupun sebaliknya masuk ke dalam sub-kelompok dan sub-budaya. Sub-sub ini menjadi salah satu faktor bagaimana high culture context dan low culture context yang terjadi di kelompok barat dan timur tidak banyak memiliki pengaruh dalam interaksi sosial di tatanan komunikasi masyarakat dunia. Sub-budaya (Mulyana \& Rakhmat, 2006) merupakan komunitas rasial, etnik, regional, ekonomi atau sosial yang memperlihatkan pola-pola perilaku yang membedakannya dari budaya mayoritas yang melingkupinya. 


\section{Imperialisme Budaya antara Barat dan Timur}

Imperialisme budaya merupakan upaya untuk menguasai negara lain melalui budaya-budaya yang ditampilkan agar terciptanya pengagungan (superior) dan penguasaan budaya ke seluruh dunia melalui berbagai cara, dimulai dari perang, jajahan dan media. Imperialisme tidak terlepas dari sejarah kolonialisme budaya barat. Kolonialisme di dunia dilakukan oleh bangsa barat kala itu untuk menguasai tanah negara yang berada di wilayah timur pada awalnya untuk menguasai rempah-rempahnya dalam motif kepentingan ekonomi, namun hal ini justru bergeser menjadi penguasaan dan penjajahan politik semata-mata untuk menjaga kepentingan perdagangan terhadap gejolak politik lokal yang dapat mengganggu kelancaran perdagangan bangsa barat.

Kolonialisme berlangsung tiga tahap yang dimulai dari era Vasco da Gama pada tahun 1498 hingga revolusi industri di Inggris pada tahun 1763 yang memperlihatkan kemunculan kuasa Eropa seperti Spanyol dan Portugis, kemudian pasca-revolusi industri hingga tahun 1870 dan yang terakhir tahun 1914 ketika terjadinya puncak Perang Dunia I. Imperialisme dalam penguasaan atas daerah jajahan menguasai negara-negara yang dianggap miskin dan terbelakang dengan tujuan mengeksploitasi sumber-sumber yang ada di negara tersebut untuk menambah kekayaan dan kekuasaan negara penjajahnya.

Imperialisme sendiri berdasar untuk menyebarkan ide-ide dan kebudayaan barat ke seluruh dunia sebagai faktor pendorong pembaharuan yang tertuju kepada pembinaan sebuah bangsa melalui pendidikan, kesehatan, undang-undang hukum dan sistem pemerintahan. Imperialisme dan kolonialisme masyarakat kelompok barat menyisakan banyak budaya artefak dan non artefak, seperti bahasa, budaya hingga jauh ke dalam sikap individu dan kelompok. Terlihat jelas dari pemaparan tersebut bahwa barat 'seakan' menjajah timur demi kepentingannya. Alasan terkuat adalah peran imperialisme orientalisme (ideologi ketimuran) dalam masyarakat kelompok barat. Hal ini menjadikan 
persilangan budaya (crossfit) secara langsung dalam konteks interaksi dan pemahaman antarbudaya. Dalam imperialisme, pandangan atas peristiwaperistiwa, gagasan maupun orang tertentu yang terjadi dapat berbeda satu sama lain yang menimbulkan prasangka terhadap objek menjadi tidak netral. Interpretasi sikap yang dikemukakan secara berbeda menjadi pemicu persaingan hingga diskriminasi antaretnik, ras maupun budaya. Berkenaan dengan ekspansi kolonial, terdapat keminatan khusus terhadap sebuah wilayah dan populasi. Kelompok barat menyiratkan pandangan tentang identitas orang barat dengan kekuatan dan kekuasaan serta memandang kelompok timur sebagai bagian yang lemah sehingga kelompok barat memiliki otoritas penuh kepada populasi kelompok timur (Machart et al., 2016). Imperialisme barat terhadap timur melintasi literatur, arsitektur, hubungan internasional, bisnis dan perdagangan.

\section{Oksidentalisme dan Orientalisme}

Oksidentalisme merupakan pandangan oleh Hassan Hanafi seorang filsuf muslim yang menitikberatkan kepada gaya dunia barat, dalam kajian oksidentalisme membawa budaya paham-paham seperti marxisme, kapitalisme, sosialisme dan pengaruh budaya melalui musik, sastra dan budaya-budaya populer sebagai gerakan penyeimbang kajian timur dan barat dari berbagai aspeknya dengan prinsip relasi yang egaliter, transformatif, dan ilmiah (Kasdi \& Umma, 2013).

Awal mula paham ini bermula pada saat terjadinya kolonialisme barat ke budaya timur untuk memetakan wilayah kekuasaan untuk menguasai wilayah timur. Bermula dari konsep pemetaan wilayah kekuasaan, superioritas dari budaya yang akan ditonjolkan merupakan bagian-bagian yang paling mendominasi dari budaya barat seperti teknologi dan kebebasan yang dimiliki oleh masyarakat kelompok barat untuk mencapai sebuah puncak tatanan imperialisme. Berbanding terbalik dengan budaya timur yang bersumber agamis, bernilai tradisional dan berusaha mengembalikan kodrat manusia dengan alam dan takdir Tuhan melalui agama dan kebudayaan masyarakat kelompok timur. 
Namun terkadang apa yang tersembunyi antara label timur dan barat seringkali tidak jelas. Paham oksidental dalam usungan Hanafi tidak dapat dilepaskan dari tiga pilar pemikirannya yaitu sikap kritis terhadap tradisi lama yang dimiliki timur, sikap kritis terhadap barat serta sikap kritis terhadap realitas. Oksidentalisme sering berarti Amerika Serikat dan negara-negara penting secara simbolis di Eropa atau Uni Eropa. M engenai timur, sering kali hanya China dan dunia muslim atau penggabungan imajinasi negara-negara yang terletak di wilayah timur (Carrier, 1995; Machart et al., 2016). Paham oriental bermula dari puncak kolonial yang dilakukan kelompok barat ke kelompok dengan budaya lain (budaya timur) yang menjadi sebuah akar kajian akademis dari pemahaman para kelompok barat.

Orientalisme pada awalnya bergerak mengkaji tentang geografis yang dimiliki wilayah timur, agama, sejarah, bahasa hingga mengenai budaya tradisional yang dilakukan oleh kelompok timur, namun menjadi tidak terkendali ketika orientalisme menjadi pusat dominasi kekuasaan dan politik sehingga memunculkan topik-topik diskriminasi atas kelompok timur dan melemahkan kebudayaan timur oleh kelompok barat. Sehingga terjadi perlawanan oleh kelompok timur untuk mengembalikan nama baik timur dengan cara mengkotakkan secara sistematis menyalahkan barat untuk memberdayakan kembali budaya timur. misalnya mengasosiasikan orang-orang kelompok timur denga nilai atau minat yang lebih filosofis dan religius dibandingkan kelompok barat, atau penggambaran kelompok timur lebih pekerja keras dan berdedikasi. Sebaliknya, kelompok barat digambarkan lebih condong ke kegiatan rekreasi dan tunduk pada nilai-nilai individualistis. Kondisi ini juga membentuk upaya bagi kelompok timur untuk melakukan imperialisme budaya timur ke masyarakat kelompok barat dengan sudut pandang westophobia sebagai suatu sikap yang melanggengkan dan memperkuat ketidakseimbangan antara dua entitas barat dan timur serta gaya berpikir yang mengkritik dan melawan semua bentuk 
kekerasan dan ketidakadilan yang diakibatkan oleh adanya dominasi kekuasaan barat.

Dalam perkembangan globalisasi yang kini pesat, menjadikan barat seolah menguasai dunia dan ingin menjadikan budaya barat sebagai hegemoni budaya, sehingga budaya timur seakan menjadi budaya terbelakang. Hal ini dikritisi oleh Said seorang cendikiawan dan sastrawan (Lary, 2007; Said, 2005), yang mengungkapkan bahwa baik sudut pandang oksidental dan oriental cenderung dalam satu arah, menuju cara superioritas, menyampingkan kemanusiaan dengan mengecualikan dan merendahkan orang lain sehingga menjadi sebuah konotasi. Ambiguitas antara oksidentalisme dan orientalisme ini terjadi karena cara pandang kelompok yang terjajah dan dijajah pada masa kolonial sehingga menimbulkan prasangka dan konflik sentimental yang tersisa hingga saat ini. Konflik pemahaman atas budaya barat dan timur berakar dari sejarah yang melatarbelakangi.

\section{Komunikasi Antarbudaya}

Komunikasi antarbudaya terjadi apabila pesan yang disampaikan oleh suatu anggota budaya diterima pesannya oleh anggota suatu budaya lainnya. Dalam keadaan ini, akan menjadi sebuah masalah situasi pesan komunikasi akan diinterpretasikan dan dimaknai secara individu maupun kelompok dalam suatu budaya dan diinterpretasikan kembali ke dalam bentuk budaya lain yang lebih luas dan kompleks. Budaya dalam komunikasi sangat mempengaruhi dan bertanggung jawab atas perbendaharaan makna komunikasi yang dimiliki oleh anggota budaya yang berinteraksi. Konsekuensinya, perbendaharaanperbendaharaan (persepsi) yang dimiliki individu dan kelompok yang berbeda budaya akan mengalami kesulitan bahkan konflik karena perbedaan yang dialami. Persepsi sosial adalah proses pemberian makna kepada objek-objek sosial dan peristiwa (Mulyana \& Rakhmat, 2006). Dalam komunikasi budaya juga terdapat unsur-unsur sosio budaya, unsur tersebut terdiri atas tiga bentuk, yaitu 
(1) sistem-sistem kepercayaan (belief) (2) nilai (value) (3) sikap (attitude); pandangan dunia (world view), dan organisasi sosial (social organization). Unsurunsur tersebut mempengaruhi persepsi yang dibangun secara individu dan bersifat pribadi serta subjektif. Ketiga unsur ini dapat masuk ke dalam etika komunikasi yang terbangun melalui proses panjang dari intrapersonal menuju interpersonal dan memiliki pengaruh terhadap persepsi sosial dalam media. Kepercayaan secara umum dapat dipandang sebagai kemungkinan subjektif yang diyakini individu bahwa suatu objek atau peristiwa memiliki karateristik tertentu, sedangkan nilai-nilai budaya berasal dari isu-isu yang filosofis yang menjadi rujukan anggota budaya tentang baik buruk, positif negatif dan salah benar. Kepercayaan dan nilai mempengaruhi sikap, sebagai bentuk kecenderungan perilaku yang diperoleh dari respon yang dipelajari dalam suatu konteks budaya yang dapat menimbulkan bias.

\section{Interaksi Sosial}

Dalam kesehariannya, setiap manusia tidak terlepas dari komunikasi, manusia berinteraksi untuk menghasilkan pergaulan sosial baik interpersonal maupun kelompok dan organisasi dalam sosial. Pergaulan hidup akan terjadi ketika individu atau kelompok bekerja sama, saling berbicara untuk mencapai tujuan bersama, mengadakan persaingan, pertikaian dan lain-lain (Setiadi, 2012) maka dapat diartikan bahwa interaksi sosial adalah proses-proses komunikasi yang berlangsung dalam sosial yang menunjuk kepada hubungan yang dinamis. Perkembangan era teknologi ini sangat memudahkan setiap orang untuk berinteraksi, jarak yang jauh tidak menjadi penghalang. Pertukaran informasi yang terjadi di media sosial menjadi sangat massive namun mengandung banyak perbedaan makna yang diinterpretasikan. Interaksi sosial antara masyarakat budaya barat dan masyarakat budaya timur seringkali berbenturan akibat interaksi yang salah pemaknaan dan malah berujung pertengkaran individu dan kelompok yang berbeda budaya. 
Dampak dari globalisasi interaksi yang merubuhkan tembok batas ruang jarak dan sudut pandang manusia adalah tidak terkendalinya miss information dan miss perception yang terbentuk. Sebenarnya, interaksi sosial hanya sebuah proses komunikasi yang merupakan syarat utama dari beragamnya aktivitasaktivitas komunikasi antar individu dan kelompok yang terbangun, namun interaksi tersebut menjadi lebih mencolok apabila timbul pertentangan antara kepentingan-kepentingan pribadi dan kelompok. Menurut Gillin dan Gillin (Setiadi, 2012) bentuk-bentuk interaksi sosial dapat berupa kerja sama (cooperation), persaingan (competition) dan pertentangan (conflict) secara lebih luas lagi dijabarkan menjadi dua macam proses interaksi sosial yaitu (a) Proses Asosiatif yang terdiri dalam tiga bentuk khusus yaitu akomodasi, asimilasi dan akulturasi (b) Proses Disosiatif mencakup persaingan yang meliputi contravention dan pertentangan pertikaian. Perbedaan yang mencolok antara kelompok masyarakat barat dan kelompok masyarakat timur muncul dari segi sikap dan pandangan terhadap sebuah peristiwa. Benturan kepentingan imperialisme budaya dari terpaan pesan-pesan media yang dilakukan oleh kedua belah pihak dapat menimbulkan pertentangan. Jenis-jenis dari pertentangan masyarakat kelompok budaya ini dimulai dari pertentangan pribadi, pertentangan rasional (ras), pertentangan kelas sosial hingga pertentangan politik.

\section{Studi Kasus}

Bagi masyarakat kelompok barat, konten yang dibuat berdasarkan kebebasan, hasil seni yang tidak berpatokan dengan nilai-nilai agamis, dan menjunjung tinggi nilai demokrasi seperti kampanye-kampanye dan propaganda universal misalnya pluralisme, hal-hal sensitif yang menyinggung seperti isu politik, propaganda, konspirasi dan lain sebagainya (Flew \& losifidis, 2020). Konten media budaya barat seperti reality show, ajang pencarian bakat, terpaan berita menjadi konsumsi media yang layak untuk ditayangkan. Imperialisme budaya yang ditonjolkan oleh budaya barat melalui penyebaran informasi adalah cara 
pandang mereka yang mengusung kebebasan tanpa harus bersinggungan dengan agama dan norma-norma yang dianggap tabu, kelompok budaya barat sangat ingin menunjukkan superioritas atas budaya yang dimilikinya, karena kelompok masyarakat timur yang hampir sebagian besar menjadi negara jajahan kolonialisme bangsa budaya barat telah memiliki faktor sugesti dari interaksi sosial yang telah dibangun pada masa penjajahan.

Pertentangan dan benturan atas imperialisme budaya barat dan budaya timur terjadi sangat agresif. Contohnya seperti ajang beauty pageants Miss World, Miss Universe dan lainnya yang sempat menjadi polemik di media sosial masyarakat Indonesia karena adanya sesi swimsuit yang bertolak belakang dari segi norma budaya timur yang mengharuskan perempuan berpakaian tertutup dan sopan. Norma ini dipengaruhi oleh agama khas timur seperti Islam salah satunya. Hal ini disebabkan karena pada umumnya tidak semua anggota masyarakat mampu mengadopsi dan beradaptasi terhadap perubahanperubahan budaya yang diperlihatkan (inferior), sehingga menimbulkan gesekan atau konflik baik kebudayaan yang ditimbulkan secara alami maupun direkayasa melalui media massa dan media sosial (Ridho, 2013). Terlebih lagi, imperialisme budaya barat semakin gencar diperlihatkan melalui tiga besar industri media sosial (Facebook, Youtube, Instagram) yang menunjukkan propaganda \#PrideM onth yaitu dukungan terhadap LGBT yang ditandai dengan banyaknya komunitas LGBT di negara barat yang menyuarakan kesetaraan yang secara teoritis dapat memicu pertentangan sosial dan politik, namun melalui media sosial, kompleksitas tersebut tersampingkan dengan perlawanan yang terkonvergensi di media sosial menggunakan hashtag atau tagar (tanda pagar) untuk menyuarakan aksi (de Ridder, 2012; Marston, 2019) dengan adanya propaganda tersebut, kelompok masyarakat budaya timur yang memiliki akun tersebut banyak yang bereaksi akibat benturan imperialisme budaya ini akibat faktor konflik atas dasar pertentangan politik (Rahman, 2010). 
Masyarakat kelompok timur yang memiliki akun media sosial tersebut mau tidak mau mengikuti imperialisme budaya ini karena banyak faktor yang melatarbelakangi. Salah satu masyarakat kelompok timur yang memproduksi dan mengadaptasi dengan baik produk imperialisme budaya barat sebagai bagian dari asimilasi budaya adalah negara maju seperti Korea Selatan, kehadiran musik K-Pop sebagai kultur baru di era perkembangan musik modern di negaranya, Korea Selatan selalu mengadaptasi hal-hal imperialisme budaya barat melalui pesan-pesan semiotika, gaya bahasa dan tingkah laku atau sikap, untuk menyeimbangkan budaya ketimuran Korea Selatan menyebarkan kebudayaan melalui bahasa, kuliner dan kebudayaan tradisional (Jin, 2007). Negara yang berada di timur seperti Jepang juga membawa kebudayaan populer dalam acara televisi, anime, manga, Japan Pop, berbagai informasi kuliner dan pariwisata Jepang sebagai imperialisme budaya (Lukacs, 2010). Negara-negara lainnya yang di wilayah timur memberikan ruang bagi imperialisme budaya timur ke budaya barat dikembangkan melalui media dakwah, musik tradisional, bentuk promosi pariwisata dan film dokumenter mengenai etnis dan budaya khas ketimuran yang dimasukkan ke dalam media sosial sebagai konten yang 'menyerang' imperialisme dari kelompok budaya barat.

M elalui tentangan tersebut, budaya barat yang terkesan glamour seakan mampu tergerus oleh budaya timur yang menerapkan keramahan terhadap alam, yang pada saat ini budaya barat tidak memilikinya akibat perkembangan dari era revolusi industri maka cara memikat masyarakat kelompok budaya timur melalui media promosi lebih menekankan budaya-budaya asli yang masih dipertahankan, melalui musik tradisional, masyarakat kelompok barat selalu mengadaptasi musik-musik pop kulturnya dengan iringan-iringan musik khas ketimuran, namun berbenturan dengan budaya ekonomi barat yang memiliki kendali besar dalam pangsa pasar dunia, jika dikaitkan, hal maka akan menghilangkan sedikit demi sedikit keaslian dan kehebatan barat, namun dalam 
prinsip ekonomi, perputaran uang kapitalisme dan fanatisme terhadap barat harus tetap dilanjutkan untuk 'menjajah' masyarakat kelompok timur.

Benturan yang ditimbulkan oleh imperialisme budaya timur ke budaya barat juga menekankan dari segi agama (Parker Gumucio, 2008), agama sangat penting dalam memahami individu dan budaya, dan agama secara inheren bersifat budaya (Cohen et al., 2016) hal ini vokal sekali dilakukan oleh budaya masyarakat timur yang harus hidup selaras dengan agama, ajaran Islam, Hindu, Budha, Konghucu dan kepercayaan timur lainnya yang berpatokan dengan alam dan dewa maupun nabi sebagai gambaran jelas bahwa penentangan akan budaya barat yang seakan anti-agama atau anti-Tuhan karena kebebasan yang mereka miliki. Budaya timur dengan ciri khasnya mulai merasuki masyarakat kelompok barat dengan tujuan mengimbangi dan mengungguli budaya barat dan mengembalikan masyarakat kelompok timur untuk tidak lepas dari ajaran budaya timur yang diluhurkan serta menunjukkan bahwa dengan pengaruh agama, banyak budaya timur bersifat kolektivis dibandingkan banyak budaya barat yang bersifat individualistis (Cohen et al., 2016).

\section{Simpulan}

Konten media sosial yang beragam dan memiliki akses tidak terbatas bagi masyarakat di seluruh dunia. Media pada awalnya hanya sebatas retorika, radio, surat kabar dan media cetak maupun media audio visual seperti televisi. Di era perkembangan digital, konvergensi media turut serta memberikan potensi besar bagi media-media lawas untuk tetap terhubung dengan konsumennya. Peleburan media-media seperti surat kabar, televisi dan radio menunjukkan bahwa ruang dari individu menerima akses informasi terus berkembang mengikuti era yang dinamis. Dalam pendahuluan telah dijelaskan konten media sosial dapat diklasifikasikan menjadi beberapa (1) kategori informasi berupa iklan, berita, tips dan trik (2) kategori hiburan berupa olahraga, otomotif, humor, video musik, drama, web series, vlog, infotainment dan reality show (3) kategori 
pendidikan berupa dakwah agama, pengetahuan umum, film dokumenter dan penelitian ilmiah. Cara penyampaian konten dapat dibagi menjadi teks, foto dan video. M edia sebagai komponen kebudayaan populer diiringi dengan konsumsi media menimbulkan efek yang luas terhadap propaganda yang dilekatkan pada ikon kultural seperti selebriti, tokoh politik, penyanyi hingga cendikiawan (Atmadja \& Aryani, 2018; Weare, 2016). Imperialisme setelah pascakolonial bukan lagi menggambarkan dalam artian kekuasaan secara menaklukan sebuah daerah atau negara tertentu, dengan seiring kemajuan informasi dan teknologi, derajat kebaruan imperialisme saat ini menuju kepada imperialism informasi dan media (Fuchs, 2010). Dalam rangkaian produksi, konten media sosial memiliki pesan yang tidak netral namun berdimensi secara ideologis dan memperkuat kekuasaan kelas atas terhadap bawah. Kekuasaan dapat bersifat mendefinisikan sebuah kebudayaan yang kuat dan memiliki pengaruh. Posisi media dalam kebudayaan dapat menggambarkan berbagai konsepsi tentang perbedaan dari kelompok-kelompok lain dan mencakup esensi terkait ideologi dominan yang berbentuk gagasan sebagai sumber pemaknaan legitimasi bagi struktur sosial termasuk dominasi dan hegemoni baik budaya barat dan budaya timur. Keduanya dapat melakukan perlawanan atau pembalikkan subjektivitas terhadap budaya lainnya (Atmadja \& Aryani, 2018; Nasrullah, 2018).

Melalui terpaan konten media sosial, imperialisme masing-masing budaya menunjukkan superioritasnya dengan tujuan yang sama, mengungguli tatanan hidup dunia dengan budaya yang ditampilkan untuk mencapai kepentingan individu dan kelompok yang berada di dalam budaya tersebut. Imperialisme budaya dalam media sosial di dalam masyarakat budaya barat dan budaya timur menunjukkan bahwa benturan antar budaya akan selalu ada dan selalu menunjukkan superioritasnya. Level komunikasi yang semakin meningkat dan dinamis dari segi teknologi membuat siapa saja dapat membuat konten media sosial dengan kampanye dan propaganda yang dimaknai didalamnya. Kebutuhan masyarakat akan informasi yang terdapat di media sosial manapun seakan 
memaksa setiap individu menyerap makna yang ada di konten yang dilihat. Imperialisme budaya dengan segala bentuk benturan dan konfliknya memiliki ruang adaptasi bagi setiap kelompok masyarakat budaya yang berbeda, hal ini menunjukkan bahwa asimilasi dan akulturasi budaya juga masuk ke dalam faktor interaksi sosial yang menjadi proses utama aktivitas komunikasi masyarakat majemuk di seluruh dunia. Perbedaan yang terjadi dapat diredam dengan penyesuaian antara budaya barat dan timur agar berjalan secara kesinambungan dan menimbulkan dampak positif bagi kepentingan individu dan kelompok.

\section{Daftar Pustaka}

\section{Buku}

Atmadja, N. B., \& Aryani, L. P. S. (2018). Sosiologi Media Perspektif Teori Kritis (1st ed.). Rajawali Press.

Carrier, J. G. (Ed.). (1995). Occidentalism: Images of the West. Clarendon Press; Oxford University Press.

Littlejohn, S. W., \& Foss, K. A. (2011). Theories of Human Communication. In Theories of Human Communication (9th ed.). Salemba Humanika.

Machart, R., Dervin, F., \& Gao, M. (Eds.). (2016). Intercultural Masquerade. Springer Berlin Heidelberg. https:// doi.org/ 10.1007/978-3-662-47056-5

Mulyana, D., \& Rakhmat, J. (2006). Komunikasi Antarbudaya (X). Remaja Rosdakarya.

Nasrullah, R. (2018). Etnografi Virtual Riset Komunikasi, Budaya dan Sosioteknologi di Internet (2nd ed.). Simbiosa Rekatama Media.

Said, E. W. (2005). Orientalism (3rd ed.). Pantheon Books, a Division of Random House Inc.

Setiadi, E. M. (2012). IImu Sosial dan Budaya Dasar (2nd ed.). Kencana Prenada Media Group.

Sulaeman, M. M. (2015). IImu Budaya Dasar. In IImu Budaya Dasar (XIII, pp. 5051). Refika Aditama.

Jurnal

Cohen, A. B., Wu, M. S., \& Miller, J. (2016). Religion and Culture: Individualism and Collectivism in the East and West. Journal of Cross-Cultural Psychology, 47(9), 1236-1249. https:// doi.org/10.1177/0022022116667895

de Ridder, S. (2012). Book Review: Christopher Pullen and Margaret Cooper, LGBT Identity and Online New M edia. New Media \& Society, 14(2), 354356. https://doi.org/10.1177/1461444811429927b 
Flew, T., \& losifidis, P. (2020). Populism, globalisation and social media. International Communication Gazette, 82(1), 7-25. https:// doi.org/10.1177/1748048519880721

Friedman, J. (2009). Occidentalism and the Categories of Hegemonic Rule. Theory, Culture \& Society, 26(7-8), 85-102. https:// doi.org/10.1177/0263276409348081

Fuchs, C. (2010). New imperialism: Information and media imperialism? Global Media and Communication, 6(1), 33-60. https:// doi.org/10.1177/1742766510362018

Jin, D. Y. (2007). Reinterpretation of cultural imperialism: Emerging domestic market vs continuing US dominance. M edia, Culture and Society, 29(5), 753-771. https://doi.org/10.1177/0163443707080535

Kasdi, A., \& Umma, F. (2013). Oksidentalisme Sebagai Pilar Pembaharuan. Fikrah, $1(2), 231-252$.

Lary, D. (2007). Edward Said: Orientalism and Occidentalism. Journal of the Canadian Historical Association, 17(2), 3-15. https:// doi.org/10.7202/016587ar

Marston, K. (2019). Researching LGBT+ Youth Intimacies and Social Media: The Strengths and Limitations of Participant-Led Visual M ethods. Qualitative Inquiry, 25(3), 278-288. https://doi.org/10.1177/1077800418806598

Parker Gumucio, C. (2008). Interculturality, Conflicts and Religion: Theoretical Perspectives. Social Compass, 55(3), 316-329. https:// doi.org/10.1177/0037768608093694

Rahman, M . (2010). Queer as Intersectionality: Theorizing Gay M uslim Identities. Sociology, 44(5), 944-961. https://doi.org/10.1177/0038038510375733

Ridho, K. (2013). Konflik Dan Tantangan Budaya Baru. Informasi, 18(02), 8.

Weare, A. M. (2016). Book Review: Fabienne Darling-Wolf, Imagining the global: Transnational media and popular culture beyond East and West. Journal of Communication Inquiry, 40(2), 196-198. https://doi.org/10.1177/0196859916630474

\section{Artikel Daring}

Hootsuite. (2020). Social Media Trend 2020. Social Media Trend 2020. https://hootsuite.com/research/social-trends?utm_campaign=allunlocking_the_value_of_social-digital_in_2020-glo-none-reportq1_2020\&utm_source=white_paper\&utm_medium $=$ owned_content\&ut m_content $=$

We Are Social, \& Hootsuite. (2018, January 30). Global Digital Report 2018. Digital in 2018: World's Internet Users Pass the 4 Billion Mark. https://wearesocial.com/blog/2018/01/global-digital-report-2018 